\title{
Dewatering characteristics of algae-containing alum sludge
}

\author{
Jill Ruhsing Pan ${ }^{a}$, Chihpin Huang ${ }^{a, *}$, Yao-Chia Chuang ${ }^{a}$, Chih-Chao Wu ${ }^{\text {b }}$ \\ a Institute of Environmental Engineering, National Chiao Tung University, Hsinchu, Taiwan, ROC \\ ${ }^{\mathrm{b}}$ Department of Environmental Engineering and Science, Feng Chia University, Taichung, Taiwan, ROC
}

Received 27 May 1998; accepted 10 November 1998

\begin{abstract}
The presence of algae in source waters not only causes problems in the water treatment process, but also complicates the treatment and disposal of sludge. This has become a major concern in Taiwan because of the increasing eutrophication of water sources. The purpose of this study was to determine the effects of algae during aging process on the characteristics of potable water treatment residuals and investigate their conditioning in order to provide water treatment plants with guidelines for treating algae-containing sludge. In this study, we measured the bound water content and CST to evaluate the influence of algae and their exudates on sludge conditioning. The change in zeta potential was monitored during sludge aging. During the aging process up to 5 days, the surface charge of sludge became more negative and the dewaterability was enhanced by algal exudates. Microphotographs of the algae-containing sludge suggest that algae and their exudates cause the bio-flocculation phenomenon. (C) 1999 Elsevier Science B.V. All rights reserved.
\end{abstract}

Keywords: Algae; Sludge; Polymer; Dilatometer; Bound water; Exudates

\section{Introduction}

Water reservoirs are the major sources of water supply in Taiwan, in which many have been polluted and become eutrophic, resulting in the problems involving algae in water treatment operations. Common problems are odor, toxicity, obstruction to coagulation and the clogging of the sand filter [1]. Like other particles in raw waters, algae are removed with traditional water treatment processes of coagulation, flocculation and sedimentation. They are eventually settled with

* Corresponding author. Tel.: + 886-35-726463; fax: + 88635-725958; e-mail: cphuang@green.ev.nctu.edu.tw. the flocs and removed from the settling basin in the form of sludge. Because of the incorporation of algae, the sludge becomes more complex and behaves like a mixture of inorganic and organic sludges. Therefore, it is reasonable to postulate that the species and quantity of algae on or in sludge affect the characteristics of sludges, such as the surface properties, moisture distribution, as well as the conditioning and dewatering characteristics.

Sludge dewatering can be influenced by many factors, such as particle size distribution, shape, specific surface area, density, particle charge, bound water content, $\mathrm{pH}$, and organic content [2]. Dulin and Knocke [3] have shown that the pres- 
ence of organic materials in the source water produces smaller flocs with more water content, resulted in poor dewaterability of the alum sludge. Konno [1] discovered that the negative surface charge on sludge particles increased with the amount of the algae and its exudates, which are also called extracellular organic mater (EOM) or exocellular polymer (EP). He also found that the sludge was most negatively charged in the logarithmic growth phase.

Sludge can be roughly divided into organic sludge, chemical or inorganic sludge, and mixed organic-inorganic sludge. O'Brien and Novak [4] have shown that inorganic sludge changed only slightly over a period of several weeks. Organic sludge, however, must be analyzed within $24 \mathrm{~h}$ of sampling in order to minimize the aging effect [3]. Pavoni et al. [5] have indicated that the biological flocculation is directly related to the production of the EOM and that maximum agglomeration occurs during endogenous growth stage resulting in the largest flocs. Li and Ganczarcyk [6] used the microphotograph to observe the influence of EOM on sludge.

The water in sludge can be generally divided into 'free water' and 'bound water'. Tsang and Vesilind [7] have further distributed this moisture into four categories: free water, interstitial water, surface water, and bound water, in which the bound water content is regarded as the theoretical limit of mechanical dewatering. Various methods have been applied in estimating the bound water content in sludge. Lee concluded that the results obtained merely reflected the operational definition with respect to the measurement methods [8]. Robinson and Knocke [9] preferred the dilatometry to the drying method because it is less timeconsuming and easy to operate. This method is based on the theory that bound water does not freeze at the temperature below the freezing point of free water. If the freezable water and the total water are known, the bound water can be calculated.

Little information is known about the correlation between the dewatering characteristics of algae-containing sludge and its fundamental properties (i.e. $\mathrm{pH}$, zeta potential, TOC content and bound water content). In fact, in our labora- tory, we have analyzed the dewatering characteristics of alum sludge in terms of bound water content [10]. Therefore, in this study, we investigate the influence of algae and their exudates on sludge conditioning and dewatering by measuring the bound water content as well as CST. Sludge aging was also a major factor considered in the experiment.

\section{Materials and methods}

Algae-containing sludge was sampled from the settling basin of chemical coagulation of the Ming-Der water treatment plant in Taichung, Taiwan. They were inorganic sludges containing large quantities of algae and small amount of other organic materials. Species of algae changes with the season, in which Pediastrum was the predominant species as observed in the microscope.

Characteristics of sludge changes significantly during the period of storage due to the presence of large quantities of algae. Sludge was stored at room temperature and covered in a plastic container to avoid direct sunlight. Aging process was monitored on unconditioned sludge samples every 2-3 days for 2 weeks. Total solids content, $\mathrm{pH}$, TOC, bound water content, zeta potential and CST value of the sludge were measured.

Three polymers, PC-320, PA-220 and T-2000, were used in sludge conditioning. PC-320 is a cationic polymer and PA-220 is an anionic polymer with similar molecular weight $\left(1.2 \times 10^{7}\right.$ in average) and charge density (20\%) which is the mole percent charged monomers as given by the manufacturer. Both polymers were purchased from the Taiwan Polymer Company. T-2000, a product of the Taiwan Calgone Corporation, is a nonionic polymer with molecular weight of $1.5 \times$ $10^{7}$. In sludge conditioning, various amount of polymer was added into a one-liter stirring apparatus containing $800 \mathrm{ml}$ sludge and then mixed for $60 \mathrm{~s}$ at $100 \mathrm{rpm}$.

Dewaterability of sludge was determined by capillary suction time (CST) using Triton CST Apparatus Model 200 with Whatman No. 17 paper filter. The supernatant was collected for zeta potential measurement with a zeta-meter sys- 
tem 3.0 from zeta-meter, USA. The operational procedure was carried out following the instruction came with the instrument and the data for zeta potential were directly read from the digital screen.

Dilatometer was employed to measure the sludge's bound water. Units for dilatometric test were modified from the one developed by Smith and Vesilind [11]. The capacity of each dilatometer was $55 \mathrm{ml}$. A total of $20 \mathrm{~g}$ of sludge sample was introduced into the dilatometer and then filled with the indicator fluid. Shell Donax TG automatic transmission fluid was chosen as the indicator fluid. The dilatometric technique in assessing sludge dewaterability had been described by Heukelekian and Weisberg [12] and the detail of the experimental procedure was given by Robinson and Knocke [9], and Smith and Vesilind [11], in which dry ice-aided ethanol bath was used to freeze the sludge samples from 20 to $-20^{\circ} \mathrm{C}$. The total water content was quantified through dry solid analysis of each sludge sample. The difference between the frozen (or free) water and the total water content was defined as the bound (or unfrozen) water content. Other details about the calculation of bound water content are described in our previous work [10].

\section{Results and discussion}

\subsection{Microscopic configuration of sludge during aging}

Fresh algae-containing sludge is yellowish brown with little odor. After storage for several days, it congealed and changed to a dark-black color with a foul smell. Fig. 1 is a $250 \times$ picture of fresh sludge, in which the green algae were found to be the major species, predominantly Pediastrum along with some Ankistrodesmus. Some diatoms, Melosira also appeared in the sludge sample. As shown in Fig. 1, particles of the fresh sludge were small and the structure of the algae was more complete. After 5 days of storage, significant flocculation was found between the sludge particles and algae, as shown in Fig. 2, and larger flocs were formed as indicated in Fig. 3. On

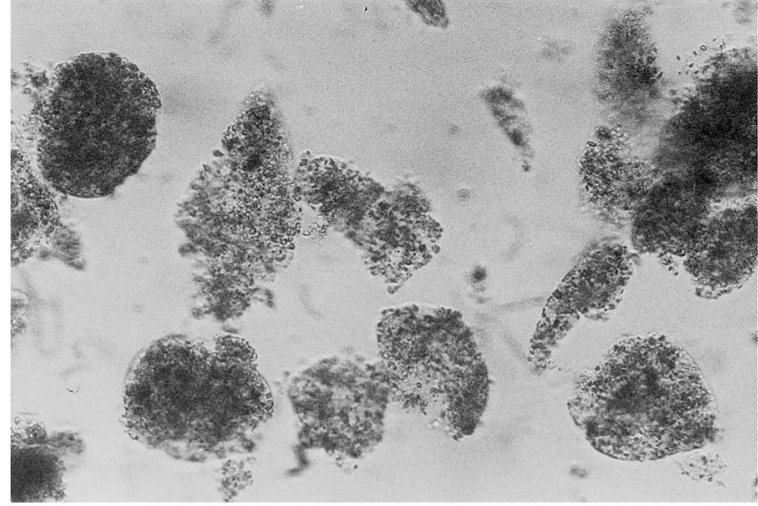

Fig. 1. Photomicrograph $(250 \times)$ of the 1 st-day sludge particles.

the 10th day, the flocculation began to breakdown, and the structure of algae was destroyed (Fig. 4).In the beginning of sludge aging, organic materials were released from the algae cells. These EOM or EP initiated the bio-flocculation between the sludge particles and algae. As the aging progressed, more EOM were released and the flocs became larger due to more advanced flocculation (Fig. 3). In the meantime, bacteria in the sludge system took part in the degradation of the algae and their EOM. As a result, the algae lost their structure and stopped producing EOM, and the phenomenon of flocculation gradually disappeared. Li and Ganczarcyk [6] have also applied the microphotographs of activated sludge to explain the effect of EOM on the formation of the

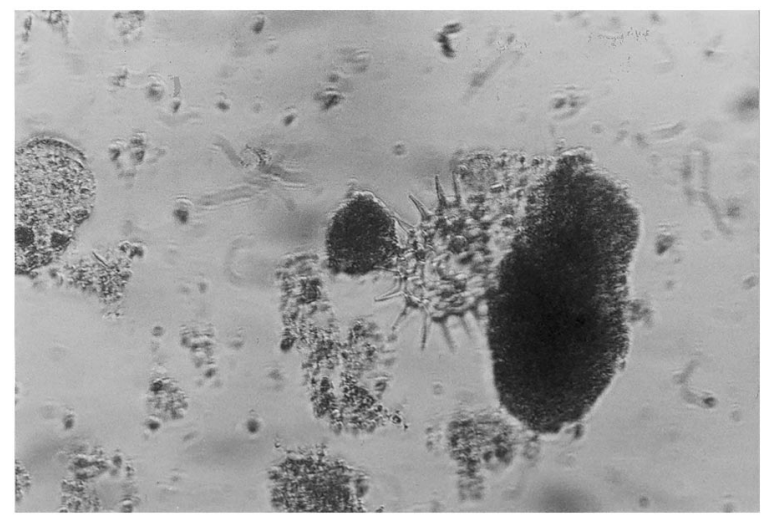

Fig. 2. Photomicrograph $(250 \times)$ of the 5 th-day sludge particles showing the bio-flocculation with Pediastrum. 


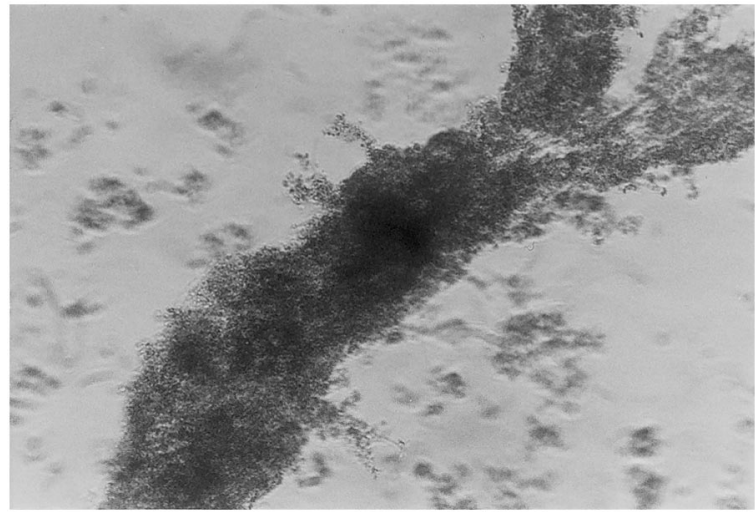

Fig. 3. Photomicrograph $(250 \times)$ of the 5 th-day sludge particles showing the enlargement of flocs through bio-flocculation.

flocs. The observation of the cells under a microscope was difficult due to the death of the algae and the resulting broken structure.

\subsection{Variations in sludge characteristics during aging}

The variations in $\mathrm{pH}$, total solid content, TOC and zeta potential of sludge during aging were monitored. The $\mathrm{pH}$ and total solid content remained unchanged through out the aging (no shown), while the TOC and bound water content decreased (Figs. 5 and 6). The decrease in TOC indicated that algae and its EOM was degraded by other bacteria and microorganisms in the dark

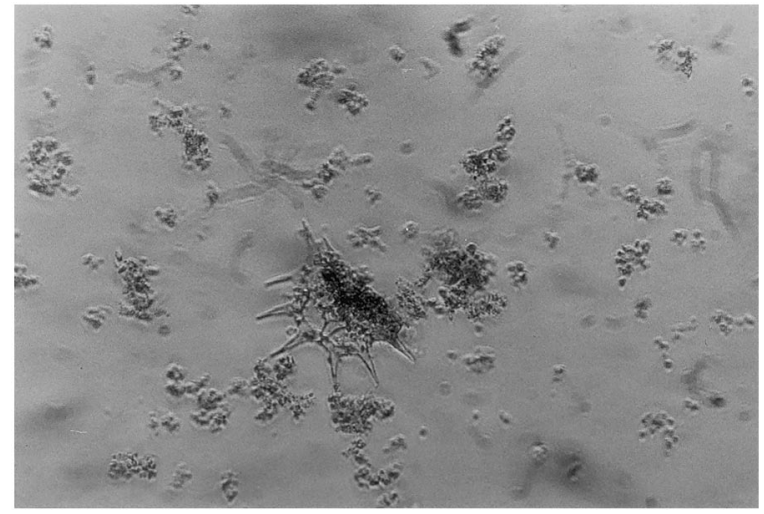

Fig. 4. Photomicrograph $(250 \times)$ of the 10 th-day sludge particles showing the degradation of algae and the breakdown of flocs.

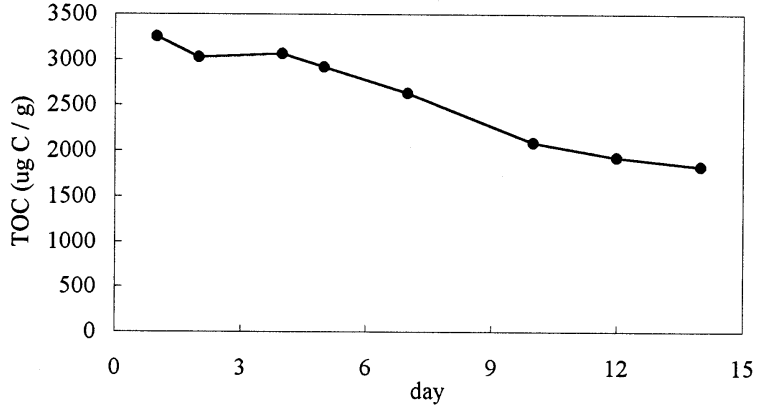

Fig. 5. TOC variation during sludge aging.

and anaerobic condition. On the basis of the microphotographical observation, we postulate a three-stage change in the bound water condition during aging. In the beginning (the first 3 days), the EOM adsorbed on the surface of sludge particle substituting the surface water and resulted in the decrease in the bound water content. As aging progressed, more organic materials were produced and adsorbed, which caused the surface of the sludge particle to became hydrophilic. Therefore, more water was attracted to the floc, and the increase in bound water content was observed between day 4 and day 7. Toward the end of the aging process, algae cells and the EOM were destroyed and released the cellular water from the surface. In addition, the sludge became more hydrophobic due to less number of organic materials adsorbed on the surface and accordingly more water was expelled, as observed in the decrease in bound water content.

The variation in zeta potential of sludge particle was seen in Fig. 7. The particle started with slight

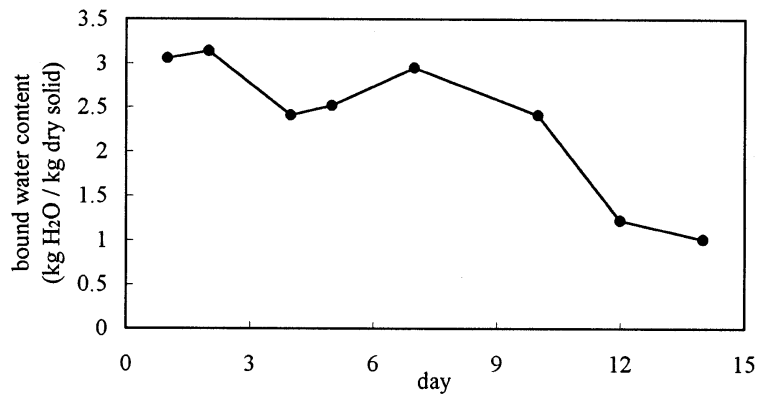

Fig. 6. Variation in bound water content during sludge aging. 


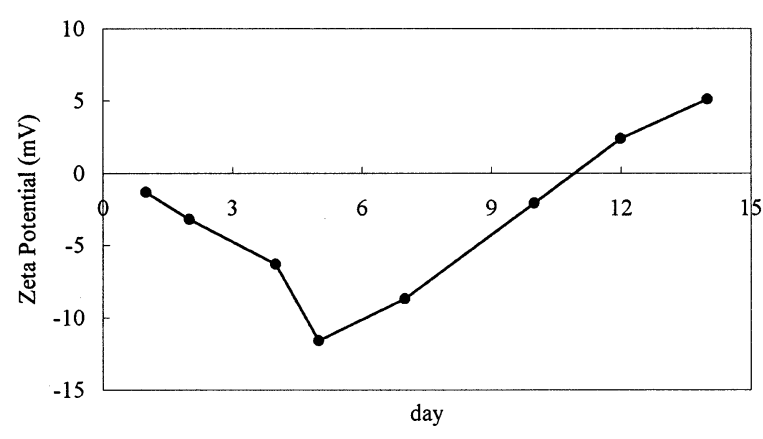

Fig. 7. Variation in zeta potential during sludge aging.

negative charge $(-1.3 \mathrm{mV})$ and the negative charge increased $-11.5 \mathrm{mV}$ at the 5 th day. After that, the surface became less negative steadily and a charge reversal was observed at 12 th day. Konno [1] also reported that the increased negative surface charge was accompanied by the increase in algogenic mucous. Algae and EOM, bearing negative charge, was destroyed gradually by bacteria and microorganisms in the sludge system, decreasing the TOC content and leading the zeta potential from negative to positive. Fig. 8 showed that the CST gradually decreased and reached the lowest value between the 5 th and 7 th day. This improvement in dewaterability of sludge was because of the formation of larger flocs caused by bio-flocculation. The parallelism between Figs. 7 and 8 further confirm this theory. The decreasing dewaterability in the later stage was due to the break down of the sludge floc.

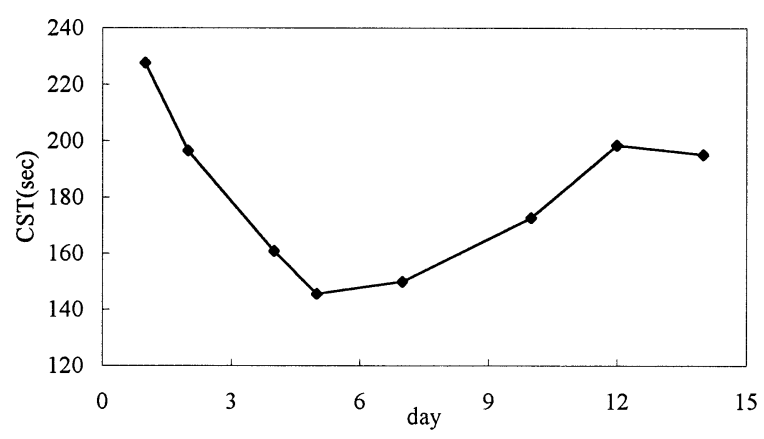

Fig. 8. Variation in CST during sludge aging.

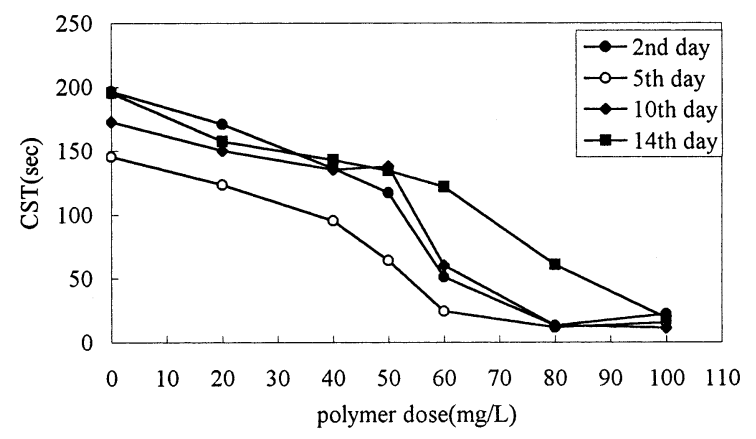

Fig. 9. The effect of sludge aging on sludge conditioning.

\subsection{Effect of aging on sludge conditioning}

The above results suggested that aging would influence the optimal dosage of sludge conditioning. This was tested by adding various amount of PC-320 to sludges from different stage of aging. Fig. 9 shows that the minimum polymer dosage was found in the 5 th day sludge, in which the most negative surface charge and the least CST were found (As shown in Figs. 7 and 8). This can be explained by the surface property of the sludge. Sludge conditioning by polymer involves both charge neutralization and bridging. Cationic polymer first destabilizes the sludge particle by neutralizing the negative surface charge. The following bridging by the polymer caused flocculation and accomplished the process of sludge conditioning. The coincidence of the minimum polymer dosage with the maximum production of EOM around the 5th day suggested that the algae and its exudates were responsible for the improvement in sludge conditioning and dewaterability in the aging process. At later stage, the algae and EOM were destroyed and therefore more polymer was required for sludge conditioning due to the lack of bio-flocculation.

\subsection{Effect of different polymer in sludge conditioning}

To further prove the significance of charge neutralization on the conditioning of algae-containing sludge, the effect of different polymer were studied. The 2-day sludge with zeta potential of approximately $-2 \mathrm{mV}$ was used in the experiment. 


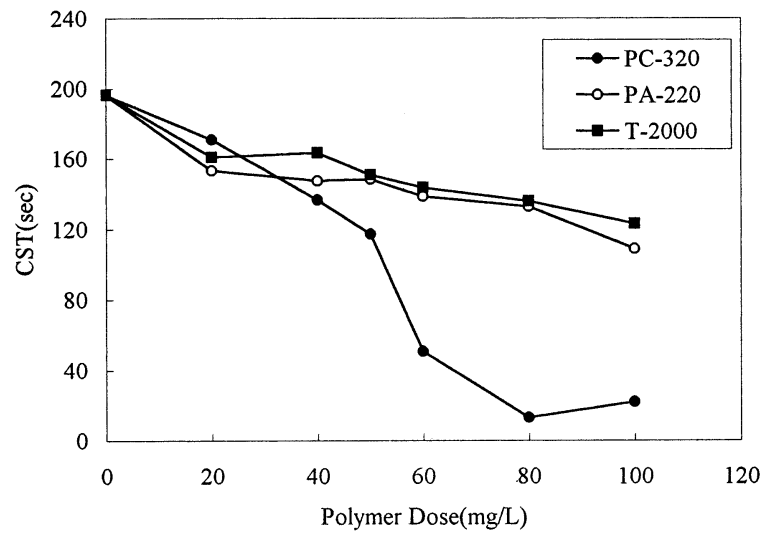

Fig. 10. The effect of different types of polymers on sludge conditioning.

Fig. 10 shows the effect of various type of polymer on CST. It is obvious that the cationic polymer (PC-320) had the best performance, although both anionic (PA-220) and nonionic (T-2000) polymer somewhat improved the sludge dewaterability. The minimum CST of the cationic polymer occurred at $80 \mathrm{mg}^{-1}$, which was defined as the optimal dose. From the operational point of view, it is easier to decide an optimal dose for cationic polymer than anionic polymer or nonionic polymer by determining from the lowest value of CST.

\section{Conclusion}

During aging, algae and its exudates changed the surface property of the algae-containing sludge, which in turn affect the sludge conditioning. It is postulated that the enhanced bio-flocculation and dewaterability as observed by lower CST in the early stage of aging is mainly caused by charge neutralization. The best performance on dewaterability by cationic polymer further confirms the significance of charge neutralization on sludge conditioning.

\section{Acknowledgements}

This work is fully supported by the grant of National Science Council, ROC.

\section{References}

[1] H. Konno, Water Sci. Tech. 27 (1993) 231.

[2] P.R. Karr, T.M. Keinath, J. WPCF 50 (1978) 1911.

[3] B.E. Dulin, W.R. Knocke, J. AWWA 81 (1989) 74.

[4] J.H. O’ Brien, J.T. Novak, J. AWWA 69 (1977) 600.

[5] Pavoni, J.L., Tenney, M.W., Echelberger, W.F., J. WPCF 44 (1972) 414.

[6] D.H. Li, J. Ganczarczyk, Biotechnol. Bioeng. 35 (1990) 57.

[7] K.P. Tsang, P.A. Vesilind, Water. Sci. Tech. 22 (1990) 135.

[8] D.J. Lee, Y.H. Hsu, Water Environ. Res. 67 (1995) 310.

[9] J. Robinson, W.R. Knocke, Water Environ. Res. 64 (1992) 60

[10] C.C. Wu, C. Huang, D.J. Lee, Colloids Surf. 122 (1997) 89.

[11] J.K. Smith, P.A. Vesilind, Water Res. 29 (1995) 2621.

[12] H. Heukelekian, E. Weisberg, Sew. Ind. Wastes 28 (1956) 558. 